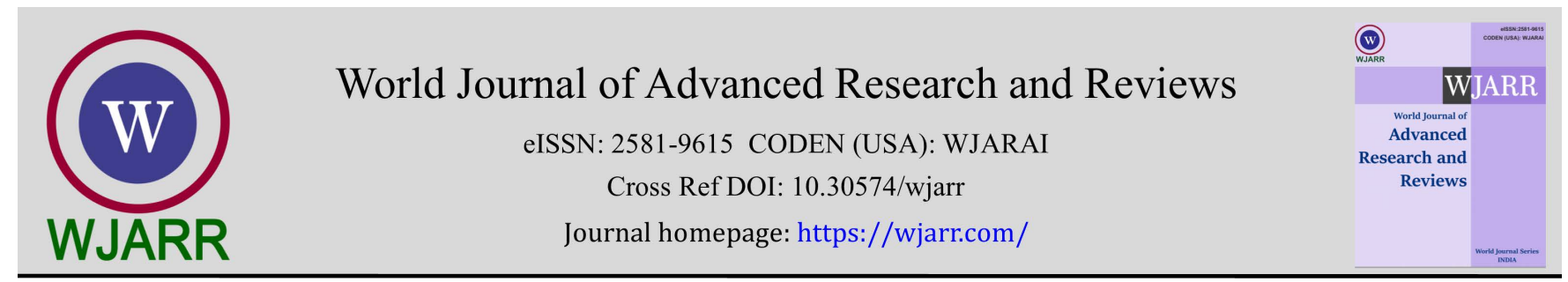

(REVIEW ARTICLE)

Check for updates

\title{
Carbon monoxide poisoning or "Silent killer": Diagnosis and current management
}

Daniela Carolina Salcedo Restrepo 1, ${ }^{*}$, Andrea Carolina Wilcox Robles 2, Armando Hongming Yee Acendra 3, Martha Lucia Beltran Avilez 4, Jorge Julian Mendoza Anguila 5, Andrés Felipe Salas Ramírez 6, John Edinson Pérez Ortega ${ }^{7}$ and Guillermo Contento Suescun ${ }^{8}$

1 General Physician, Universidad Del Sinú, Montería.

${ }^{2}$ General Physician, Universidad Libre de Barranquilla, Colombia.

${ }^{3}$ General Physician, Fundación Universitaria San Martín de Barranquilla, Colombia.

${ }^{4}$ General Physician, Universidad de Sucre, Colombia.

${ }^{5}$ General Physician, Universidad Cooperativa de Colombia, Sede Santa Marta.

${ }^{6}$ General Physician, Fundación Universitaria Juan N. Corpas, Bogotá.

${ }^{7}$ General Physician, Universidad Autónoma de Bucaramanga.

${ }^{8}$ General Physician, Universidad de Boyacá, Colombia.

World Journal of Advanced Research and Reviews, 2021, 12(03), 522-527

Publication history: Received on 09 November 2021; revised on 13 December 2021; accepted on 15 December 2021

Article DOI: https://doi.org/10.30574/wjarr.2021.12.3.0693

\begin{abstract}
Carbon monoxide poisoning is a dangerous cause of hospital admission and mortality around the world due to its ability to enter the body and bind to heme groups. Thus, it is important to carry out a correct management plan for this type of patient, in order to avoid and prevent the development of severe systemic complications and even death, for which a review of diagnostic techniques is carried out and treatment of this scenario and its effectiveness in terms of the evolution of the patient.
\end{abstract}

Keywords: Carbon monoxide; Poisoning; Diagnosis; Management

\section{Introduction}

Carbon Monoxide (CO) is a colorless, odorless, and non-irritating gas that is absorbed through the lungs. It arises from the incomplete burning of hydrocarbons [1]. Its absorption rate depends on the duration of exposure, the concentration of $\mathrm{CO}$ found in the environment and minute ventilation [2]. When reviewing data on injuries and deaths after poisoning around the world, CO poisoning is the most common cause [3]. The causes of such accidental poisoning are open fires $(42 \%)$, exposure related to work in the industry $(26 \%)$ and defective furnaces $(19 \%)$. Motor vehicles only correspond to a small proportion (4\%) (Table 1) of which $88 \%$ represent the result of a suicide attempt [4]. The high morbidity and mortality are face to face with the risk of neglect due to nonspecific symptoms and difficulties at the time of their detection [5].

\footnotetext{
* Corresponding author: Daniela Carolina Salcedo Restrepo

General Physician, Universidad Del Sinú, Montería.

Copyright ( $(2) 21$ Author(s) retain the copyright of this article. This article is published under the terms of the Creative Commons Attribution Liscense 4.0.
} 
Table 1 Causes and percentages of CO exposure poisoning

\begin{tabular}{|l|c|}
\hline Cause & $\mathbf{\%}$ \\
\hline Open fires & $42 \%$ \\
\hline Industry-related work & $26 \%$ \\
\hline Faulty furnaces & $19 \%$ \\
\hline Motor vehicles & $4 \%$ \\
\hline
\end{tabular}

The toxicity presented by $\mathrm{CO}$ is the result of a combination of tissue hypoxia-ischemia due to the formation of $\mathrm{COHb}$ and direct cellular damage by CO. Ischemia in the arterial border areas of the brain is the consequence of hypotension with CO poisoning. Areas of the brain affected by hypoxia secondary to CO include the cortex, layers three, four, and five, the hippocampus, white matter, basal nuclei, and Purkinje cells in the cerebellum [6]. Its affinity for hemoglobin molecules is approximately 240 times greater than that of oxygen, leading when it presents the formation of carboxyhemoglobin by replacing the coupled 02. Once inhaled, $\mathrm{CO}$ leads to tissue hypoxia that mainly affects areas of high blood flow and oxygen demand. The mechanism of CO toxicity begins with entry into the blood through the lungs and $10-15 \%$ is bound to heme-containing proteins, particularly cytochrome c oxidase and myoglobin. The affinity of CO for myoglobin is also 60 times greater than that of 02 causing cardiac depression and potentially hypotension [7]. Increased oxidative stress is the consequence of inflammation caused by CO through increased concentration of cytosolic heme and heme oxygenase-1 protein. By presenting the function of the heme platelet protein, CO causes the release of nitric oxide that leads to an altered mitochondrial function and an increase in tissue hypoxia due to the formation of peroxynitrite. Such CO exposure increases oxidative stress, lipid peroxidation, and apoptosis through platelet-neutrophils, neutrophil aggregation and degranulation, release of myeloperoxidase, proteases, and reactive oxygen spices. Xanthine dehydrogenase interacts with proteins in endothelial cells, forming xanthine oxygenase that inhibits mechanisms against oxidative stress. CO-induced hypoxia activates hypoxia-inducible factor $1 \mathrm{a}$, which can affect protective or deleterious gene normalization depending on the CO dose and factors in the previously exposed individual [8].

Table 2 Most important parameters for diagnosing and treating CO-intoxication

\begin{tabular}{|l|l|}
\hline Parameters & Comment \\
\hline Carboxyhemoglobin & $\begin{array}{l}\text { Initial diagnosis of co-intoxication } \\
\text { Preclinical use with percutaneous co-oximetry. } \\
\text { No correlation to duration of inpatient treatment, severity of symptoms, prognosis }\end{array}$ \\
\hline Oxyhemoglobin & Respiratory arrest is a possible symptom of CO-intoxication \\
\hline Lactate blood level & $\begin{array}{l}\text { Tissue hypoxia } \\
\text { Correlation to time of co-exposure and severity } \\
\text { Tool to decide for HBO treatment in children }\end{array}$ \\
\hline Leucocytes & Correlation between elevated leucocytes and duration of inpatient treatment \\
\hline C-reactive protein & Correlation between increased CRP and duration of inpatient treatment \\
\hline Chest x-ray & $\begin{array}{l}\text { Lung infiltrates, lung edema - } \\
\text { Correlation between pulmonary infiltrates and severity }\end{array}$ \\
\hline $\begin{array}{l}\text { Glasgow-Coma- } \\
\text { Scale }\end{array}$ & $\begin{array}{l}\text { Possible symptoms: dizziness, confusion, seizures } \\
\text { Inverse correlation to inpatient stay and severity }\end{array}$ \\
\hline Electrocardiography & $\begin{array}{l}\text { Possible heart disorder e.g. tachycardia, QT prolongation, myocardial ischemia, ventricular } \\
\text { arrhythmia }\end{array}$ \\
\hline Bronchoscopy & \begin{tabular}{l} 
Degree of erythema, edema, ulceration \\
\hline
\end{tabular} \\
\hline
\end{tabular}


Therefore, its various clinical presentations lead to different diagnoses due to the lack of reliable blood tests correlated with the clinical outcome. To detect $\mathrm{CO}$ poisoning, the percentage of $\mathrm{COHb}$ is measured, although by itself it is not enough, therefore, the use of more tests such as leukocytes, oxyhemoglobin, C-reactive protein, lactate levels in the blood, among others that together are of very useful for diagnosing and treating CO poisoning [9]. (Table 2).

\section{Methodology}

In this review article, a detailed bibliographic search of information published since 2010 was carried out, in the databases pubmed, Elsevier, Scielo, national and international libraries. We use the following descriptors: carbon monoxide, poisoning, diagnosis, and management. The data obtained oscillate between the records after the use of the different keywords. The search for articles was carried out in English and Spanish, limited by year of publication, and studies published since 2010 were used.

\section{Results}

Several articles were identified that met the inclusion criteria for the development of the research. The clinical symptoms of acute carbon monoxide poisoning range from headache and dizziness to loss of orientation, symptoms of cardiac angina, loss of consciousness, and death. They depend on the concentration and duration of exposure. Detecting chronic poisoning with mild symptoms is often problematic, as the symptoms resemble those of influenza. In the long term, neurological lesions will manifest, for example, ataxias, dementia, concentration deficits or abnormal behavior. Changes in the subcortical and pallidus structures have been observed, as well as atrophy of the hippocampus. Several studies recommend the administration of $100 \%$ oxygen as soon as possible to all patients with a relevant suspicious diagnosis (in alert patients, for example, by continuous non-invasive airway pressure (CPAP), or respiration by means of a mask with a valve). Demand, or administration of $15 \mathrm{~L} / \mathrm{min}$ of 02 through a reservoir mask). In the event of suspected $\mathrm{CO}$ poisoning, early diagnosis plays a crucial role in initiating targeted and timely treatment. In principle, the diagnosis of $\mathrm{CO}$ poisoning is based on clinical symptoms and suspected or confirmed exposure. For verification purposes, carboxyhemoglobin ( $\mathrm{COHb}$ ) must be measured in a blood gas analysis (BGA) [9]. The ultimate goal is the elimination of carbon monoxide from the body, to avoid acute and long-term sequelae. Treatment should continue until the $\mathrm{COHb}$ measurement has dropped to normal values $(<3 \%)$ and the patient is symptom free. After exposure to fumes, and in addition to $\mathrm{CO}$, additive cyanide poisoning should also be considered, the effects of which will develop in minutes [10].

A case report presents the case of a 56-year-old man exposed to carbon monoxide from a heater in his home. In the diagnostic examination, the patient was found unconscious, with a score of 5 on the Glasgow coma scale, also presenting respiratory failure and a smell of smoke emanating from his body. Initial treatment included endotracheal intubation, mechanical ventilation, and administration of diuretics and antiplatelet agents. The patient was treated in the intensive care unit. The carboxyhemoglobin level improved from day 1 to day 2 of the hospital stay, while the levels of troponin I and the fraction of creatine kinase-MB improved from day 1 to day 5, with a discharge certificate at 8 days of hospitalization [11]. Another case report was a 48-year-old patient who was found outside his apartment building after a fire, the patient exhibited intense smoke inhalation. The patient has a history of hypertension, no coronary artery disease, and no history of smoking. Upon his arrival (day 1), the patient was immediately placed in a non-rebreather mask for the delivery of $100 \%$ high concentration oxygen. After continuous oxygenation and fluid resuscitation, the patient was transferred back to the medical floor on day 7. The patient was discharged on day 8 with low-dose aspirin and statins. At the follow-up in the pulmonary clinic one month later, the general condition of the patient was found to be good, with no cognitive dysfunction or neurological deficits [12].

Regarding the treatment of CO poisoning with hyperbaric oxygen therapy (HBOT), it has been found to be beneficial in reducing the risk of cognitive deficits. Hyperbaric oxygen (HBO2) accelerates the elimination of carboxyhemoglobin $(\mathrm{COHb})$ and favorably modulates the inflammatory processes caused by $\mathrm{CO}$ poisoning, an effect not seen with normobaric oxygen respiration. Hyperbaric oxygen improves mitochondrial function, transiently inhibits lipid peroxidation, alters leukocyte adhesion to injured microvasculature, and reduces brain inflammation caused by COinduced myelin basic protein adduct formation [13].

\section{Discussion}

Due to the diverse and varied sources of exposure to carbon monoxide, and its easy entry into the body, this constitutes one of the main emergencies that occur at the hospital level, and the second most common cause of mortality in several 
countries, among which The United States stands out, because its ease lies in the fact that it is eliminated from vehicles, cigarette smoke, and appliances that run on gas, gasoline, or burning wood.

Regarding its pathophysiology and toxicity, this depends essentially on the special affinity it has for the heme groups of proteins, such as globins (hemoglobin, myoglobin) and for cytochromes of mitochondrial respiratory enzymes (CYP 450 and A3) and NADPH reductase. In addition, it produces an interruption in oxygen transport and precipitates the inflammatory cascade. It also produces the peroxidation of brain lipids, which causes loss of consciousness. The alteration of myoglobin produces disorders of cellular metabolism and rhabdomyolysis, in addition to tissue hypoxia due to alteration of cellular metabolism [14].

Its clinical manifestations mainly include neurological, respiratory and cardiovascular (Table 3) such as headache, vertigo, dizziness, nausea / vomiting, drowsiness, lethargy, confusion, visual disturbances (blurred vision), chest pain, muscle weakness, abdominal pain, mydriasis, neurological involvement, coma, heart failure, shortness of breath, seizures, hydrocephalus, and ultimately death; and these patients present a characteristic sign known as cherry skin.

Table 3 Symptoms according to hypoxia in each system. Oliu, G. Nogué, S. Miró, 0. 2010

\begin{tabular}{|c|c|c|}
\hline Central Nervous System & Cardiovascular system & Systemic symptoms \\
\hline $\begin{array}{l}\text { Headache, syncope, fainting, decreased } \\
\text { level of consciousness, seizures, ataxia, } \\
\text { behavioral disturbances, dizziness, } \\
\text { feeling of instability, loss of strength. }\end{array}$ & $\begin{array}{l}\text { Palpitations, chest tightness, heart rhythm } \\
\text { disturbances, cardiac ischemia. } \\
\text { Cardiorespiratory arrest due to severe } \\
\text { cardiac hypoxia or brain stem involvement. }\end{array}$ & $\begin{array}{l}\text { Nausea, vomiting, diarrhea, } \\
\text { asthenia, } \\
\text { rhabdomyolysis, } \quad \text { muscle } \\
\text { impotence. }\end{array}$ \\
\hline
\end{tabular}

Taking into account its high degree of mortality and the great systemic commitment that it triggers, a fast and efficient management plan is necessary for the management of this type of patients, beginning with a diagnosis with an interview with family members or companions, corroborating exposure to Monoxide from different sources, environmental conditions, water heaters, faulty heating systems and imminent fire, in addition to the time to which the patient was exposed, since this in turn determines the severity and degree of intoxication that the patient presents. For all this, the carboxyhemoglobin test is carried out to detect CO poisoning in an early, mild, acute and chronic way, and its main treatment is carried out, consisting of oxygen therapy, since the density of the oxygen molecules in comparison with $\mathrm{CO}$ molecules in hemoglobin have a higher affinity and favor the formation of $02 \mathrm{Hb}$ [15].

In their descriptive cross-sectional study of consultations registered at the Toxicological Information and Advice Center (CIAT) between January 1 and December 31, 2017, Noel and others, taking into account the results obtained after analyzing several cases, concluded that The permanence in spaces with combustion heating and the use of a gas heater are the typical scenarios of intoxication and that headache is a key symptom to investigate exposure [16], which makes it even more necessary to be correct both differential and of intoxication and its correct treatment.

In their presentation of a clinical case, Guirola et al., Present the case of a 19-year-old patient, a worker, who in an initial consultation, his clinical picture was interpreted as a hypersensitivity reaction; Steroids and antihistamines were administered intravenously and then he was discharged. An hour later, he clinically worsened and went back to the health services in primary care. He was referred to the hospital. He is received in the guardhouse of the Military Hospital "Dr. Mario Muñoz" with a history of exposure to gases from the combustion of a vehicle. With the clinical picture, he was diagnosed with acute $\mathrm{CO}$ poisoning [17] and later he was given the necessary treatment, however, despite the fact that the patient did not die, the present negligence is evident, and the imperative need to implement measures as quickly as possible, since by making a timely diagnosis of this acute poisoning, in which there is a minimum time between exposure, diagnosis and treatment, a favorable evolution of the patient is possible, avoiding fatal complications.

During the intoxication process, it is also very important to carry out a post-discharge follow-up in those patients admitted for this cause, since it has been shown that in the long term there are neurological repercussions caused by this, as stated by Bartolomé et al., In their case report, where they comment that these patients are not usually reviewed, they are not followed-up post-discharge and in $20-30 \%$ of the cases, according to different cases, they present a Late Neurological Syndrome (NTS), a syndrome that appears between on days 2 and 28 after intoxication, often after a period of normalcy. This syndrome includes: peripheral neuropathy, alterations in personality, behavior, memory, gait, etc [18]. In addition, the effectiveness of treatment based on the administration of normobaric oxygen is evaluated and studied. 
The administration of normobaric oxygen is fully supported by Zaragoza and others, who present a delicate case of carbon monoxide poisoning in a pregnant patient, management of $100 \%$ normobaric oxygen was started, which reduces the half-life of the monoxide between 30 and 90 minutes. This treatment should be rapid, bearing in mind that pregnant women are a population at risk of carbon monoxide poisoning and that the increase in carboxyhemoglobin in the mother creates a gradient that allows carbon monoxide to cross the placenta and bind to hemoglobin. Fetal, which shows an affinity even greater than adult hemoglobin for carbon monoxide [19, 20].

However, it is estimated that a large percentage of patients treated with normobaric oxygen develop long-term neurological complications, while in patients treated with hyperbaric oxygen this proportion decreases, for which authors, such as Guirola et al., Affirm that hyperbaric oxygenation does not it only provides the necessary oxygen but also counteracts the hypoxia or anoxia that can occur in the tissues. It also provides tissue oxygenation due to the high P02 that is achieved when 02 dissolves in the plasma, and due to the rapid decrease in cerebral edema, it decreases by $50 \%$ after 2 minutes of breathing 02 at 3 ATA. Hyperbaric oxygen favors the dissociation of COHb, notably reducing its half-life and the elimination of CO from the body, while oxygenates hypoxic tissues, releases cytochrome a 3 and p450, unblocking the respiratory chain and inhibits lipid peroxidation [21] so that its application early has the ability to counteract the effects of intoxication and in turn can prevent the development of different neurological complications.

This is supported by Martinel and others, who after presenting a series of cases of patients with monoxide poisoning suggest the implementation of hyperbaric oxygen before normobaric, based on the fact that the hyperbaric oxygenation treatment performed between 1.4 and 1.5 ATA does not induce neuroexcitability, reaches a sufficient hyperoxia for cerebral blood perfusion and is considered optimal for neurological treatments, unlike normobaric oxygen, for which they conclude that HBOT therapeutic modality at 1.45 ATA (absolute atmospheres) $\approx 100 \% 02$ should be preferable to normobaric oxygen for ICO, and considered when high pressure facilities are not available at reasonable distances [22].

Finally, Instrutemp, as a preventive measure, recommends the use of gas detection devices, since when the person realizes the possible leak, they can take all the appropriate measures and therefore avoid their hospitalization, since that carbon monoxide detectors work by measuring the concentration of carbon monoxide in the environment, in parts per million (ppm). The device works through an integrated circuit, which has an electronic CO sensor. Identification of carbon monoxide build-up occurs through an electrochemical reaction, which transforms chemical energy into electrical energy. This electrical energy increases the current in the circuit, which consequently decreases resistance. It is this difference in electrical resistance in the presence of $\mathrm{CO}$ that triggers an alarm or semiconductor, warning the user of gas detection [23].

\section{Conclusion}

Carbon monoxide poisoning is the second cause of mortality in several countries in the world and one of the most frequent causes of hospital admission, due to the wide variety of sources of exposure and its ease of entry into the body. Due to the fact that it causes a series of clinical manifestations that mainly involve the respiratory, neurological and cardiovascular systems, the number of neurological complications that develop in the long term after this is evident.

Therefore, it is necessary that all health personnel have a clear diagnosis of this intoxication, which is based on the questioning of the patient and carboxyhemoglobin examination, to subsequently implement the appropriate treatment, which has consisted of the administration of normobaric oxygen, however, recent studies ensure that the administration of hyperbaric oxygen decreases more effectively and rapidly the half-life of carbon monoxide in the body, in addition to preventing neurological complications that can occur, however, this continues being the object of study.

\section{Compliance with ethical standards}

\section{Disclosure of conflict of interest}

The authors declare that they have no conflicts of interest.

\section{References}

[1] Megarbane B. Carbon monoxide intoxication in the 21st century: the battle to improve outcomes continues. Emergencias. 2019; 31(5).

[2] Weaver LK. Clinical practice. Carbon monoxide poisoning. N Engl J Med. 2009; 360: 1217-1225. 
[3] Thom SR. Hyperbaric oxygen therapy for acute carbon monoxide poisoning. N Engl J Med. 2002; 347 (14): 11056.

[4] Grieb G, Simons D, Schmitz L, Piatkowski A, Grottke O, Pallua N. GlasgowComa Scale and laboratory markers are superior to $\mathrm{COHb}$ in predicting severity of CO poisoning. Burns. 2011; 37: 610-5.

[5] Tellez J, Fajardo A. Carbon monoxide pollution: AN environmental health problem. Rev Salud Publica (Bogotá). 2006; 8 (1): 108-17.

[6] Louise W, Kao MD. Toxicity Associated with Carbon Monoxide. Clinics in Laboratory Medicine. 2006; 26(1): 99125.

[7] Silver S, Smith C, Worster A. Should you use hyperbaric oxygen for carbon monoxide poisoning? CJEM. 2006; 8 (1): 43-6.

[8] Hopkins, R, Et al. Basal ganglia lesions following carbon monoxide poisoning. Brain Injury. 2006; 20(3).

[9] Reumuth G, Et al. Carbon monoxide intoxication: What we know. Burns. 2019; 45(3): 526-530.

[10] Hampson NB, Dunn SL. CO Poisoning Surveillance Group UHMCS / CDC: Carbon monoxide poisoning symptoms do not correlate with baseline carboxyhemoglobin level. Submarine Hyperb Med. 2012; 39: 657-665.

[11] Eichborn L. The Diagnosis and Treatment of Carbon Monoxide Poisoning. Dtsch Arztebl Int. 2018; 115(51).

[12] Kara, H, Et al. Cerebrovascular ischaemia after carbon monoxide intoxication. Singapore Med J. 2015; 56(2).

[13] Jankowska D, Et al. Non-ST elevation myocardial infarction secondary to carbon monoxide intoxication. J Community Hosp Intern Med Perspect. 2017; 7(2).

[14] Weaver LK. Hyperbaric oxygen therapy for carbon monoxide poisoning. Submarine Hyperb Med. 2014; 41 (4): 339-354.

[15] Bolaños P, Chacón C. Carbon monoxide poisoning. Costa Rican legal medicine. 2017; 34 (1).

[16] Tirado C. Carbon monoxide poisoning, a systematic review of diagnosis and treatment during prehospital care. Central University of Ecuador. Degree work Bibliographic Review modality. Quito, Ecuador. 2021.

[17] Noel M, Laborde A. Carbon monoxide exposure scenarios that guide the clinical suspicion of acute poisoning. Rev Méd Urug. 2021; 37 (2): e37205.

[18] Guirola, J. Perez, L. Garcia, Y. O'Reillys, D. Guedes, R. Carbon monoxide poisoning. Cuban Journal of Military Medicine. 2019; 48 (2): 245-251.

[19] Bartolomé, M. Amores, P. Cuesta, E. Gallego, N. Carbon Monoxide Poisoning: A little valued pathology in the Emergency Department. Rev Clín Med Fam. 2010; 3 (3): 220-222.

[20] Zaragoza L, Calvo E, Sanchez D, Escalera C, Del Pino S, Perez M. Carbon monoxide poisoning in a pregnant woman: case report. Ginecol Obstet Mex. 2021; 89 (11): 891-897.

[21] Guirola J, Garcia Y, O'Rellys D, Guedes R, Cisnero Y, Cabrera A. Carbon monoxide poisoning and hyperbaric oxygen treatment. Rev Clinical Toxicology Online. 2003.

[22] Martinel F, Mastroianni C, Arredondo V, Sanchez R, Alterini P, Gonzalez M, Romero D, Arredondo C, Oxygen DoseCelerity Relationship in hyperbaric oxygenation for carbon monoxide poisoning. Acta Toxicol. Argent. $2020 ; 28$ (3): 73-81.

[23] Instrutemp. Medidores de CO podem salvar vidas: entenda como funcionam. Brasil. 24 set. 2019. 